\title{
Serum 25-hydroxyvitamin $D$, calcium and parathyroid hormone levels in Native and European populations in Greenland
}

\author{
Stig Andersen ${ }^{1,2,3,4 *}$, Paneeraq Noahsen ${ }^{1,2}$, Karsten F. Rex ${ }^{1,2}$, Inuuteq Fleischer ${ }^{1,5}$, Nadja Albertsen ${ }^{1,4}$, \\ Marit E. Jørgensen ${ }^{3,6}$, Louise K. Schæbel ${ }^{1,4}$ and Mogens B. Laursen ${ }^{5}$ \\ ${ }^{1}$ Arctic Health Research Centre, Aalborg University Hospital, 9000 Aalborg, Denmark \\ ${ }^{2}$ Department of Internal Medicine, Queen Ingrid Hospital, 3900 Nuuk, Greenland \\ ${ }^{3}$ Ilisimatusarfik, University of Greenland, 3900 Nuuk, Greenland \\ ${ }^{4}$ Department of Geriatric Medicine, Aalborg University Hospital, 9000 Aalborg, Denmark \\ ${ }^{5}$ Department of Orthopaedic Surgery, Aalborg University Hospital, 9000 Aalborg, Denmark \\ ${ }^{6}$ Steno Diabetes Centre, 2820 Gentofte, Denmark \\ (Submitted 5 June 2017 - Final revision received 19 October 2017 - Accepted 24 October 2017)
}

\section{Abstract}

Ca homoeostasis is important to human health and tightly controlled by powerful hormonal mechanisms that display ethnic variation. Ethnic variations could occur also in Arctic populations where the traditional Inuit diet is low in Ca and sun exposure is limited. We aimed to assess factors important to parathyroid hormone (PTH) and Ca in serum in Arctic populations. We included Inuit and Caucasians aged 50-69 years living in the capital city in West or in rural East Greenland. Lifestyle factors were assessed by questionnaires. The intake of Inuit diet was assessed from a FFQ. 25-Hydroxyvitamin D $\left(25 \mathrm{OHD}_{2}\right.$ and $\left.25 \mathrm{OHD}_{3}\right)$ levels were measured in serum as was albumin, Ca and PTH. The participation rate was $95 \%$, with 101 Caucasians and 434 Inuit. Median serum 25OHD (99.7\% was 25OHD 3 ) in Caucasians/Inuit was $42 / 64 \mathrm{nmol} / 1(25,75$ percentiles $25,54 / 51,81)(P<0 \cdot 001)$. Total Ca in serum was $2 \cdot 33 / 2 \cdot 29 \mathrm{mmol} / 1(25,75$ percentiles $2 \cdot 26,2 \cdot 38 / 2 \cdot 21,2 \cdot 36)$ $(P=0.01)$ and PTH was $2 \cdot 7 / 2 \cdot 2 \mathrm{pmol} / 1(25,75$ percentiles $2 \cdot 2,4 \cdot 1 / 1 \cdot 7,2 \cdot 7)(P<0 \cdot 001)$. The 69/97 Caucasians/Inuit with serum $25 \mathrm{OHD}$ $<50 \mathrm{nmol} / 1$ differed in PTH $(P=0.001)$ that rose with lower 25OHD levels in Caucasians, whereas this was not the case in Inuit. Ethnic origin influenced PTH $(\beta=0.27, P<0.001)$ and $\mathrm{Ca}(\beta=0.22, P<0.001)$ in multivariate linear regression models after adjustment for age, sex, BMI, smoking, alcohol and diet. In conclusion, ethnic origin influenced PTH, PTH response to low vitamin D levels and Ca levels in populations in Greenland. Recommendations are to evaluate mechanisms underlying the ethnic influence on Ca homoeostasis and to assess the impact of transition in dietary habits on Ca homoeostasis and skeletal health in Arctic populations.

Key words: Parathyroid hormone: Calcium: Vitamin D: Ethnicity: Inuit

Living in an Arctic environment challenges Ca homoeostasis in two ways. First, sun exposure is limited with low dermal production of vitamin $\mathrm{D}$. Second, the traditional Inuit diet is mainly of marine origin and a poor source of $\mathrm{Ca}$.

As for vitamin $\mathrm{D}$, the endogenous production of 25-hydroxyvitamin D (25OHD) depends on exposure to sunlight, and serum 25OHD levels in groups of Caucasian subjects decrease with increasing latitude ${ }^{(1-3)}$. Thus, 25OHD levels should be low in Greenland Inuit ${ }^{(4,5)}$ and it may have been a favourable trait for Arctic residents to develop mechanisms in order to adapt to lower levels of serum $25 \mathrm{OHD}^{(5-7)}$. Diet is another source of $25 \mathrm{OHD}$, with fish and sea mammals being particularly rich in vitamin $\mathrm{D}^{(8,9)}$. These dominate the traditional Inuit diet ${ }^{(5,10,11)}$, with seal and whale blubber considered to be of particular dietary value by the Inuit. The intake of these Arctic dietary components has the potential to compensate for the limited dermal 25OHD production in Arctic residents ${ }^{(5,12)}$. However, this does not provide an alternative source of $\mathrm{Ca}$ that is sparse in the dietary components that comprise the traditional Inuit diet. Thus, Canadian Inuit and Alaska Natives reported a low Ca intake ${ }^{(13,14)}$, and a low dietary Ca content in local foods in Greenland ${ }^{(15)}$ was speculated to be the cause for low serum $\mathrm{Ca}$ in Greenland Inuit ${ }^{(16)}$.

Ca intake has a limited impact on short-term Ca status of an individual as Ca level in serum is maintained within narrow limits by powerful endocrine control mechanisms ${ }^{(17)}$. These interactive homoeostatic mechanisms may have adapted to short-term low $\mathrm{Ca}$ intake, whereas long-term low $\mathrm{Ca}$ intake maintains importance for the occurrence of diseases. Thus, low parathyroid hormone (PTH) with hypocalcaemia associates with low bone turnover, infections, IHD and dental enamel hypoplasia ${ }^{(17)}$.

Abbreviations: 25OHD, 25-hydroxyvitamin D; PTH, parathyroid hormone.

* Corresponding author: S. Andersen, email stiga@dadlnet.dk 
Greenland Inuit have been reported to have a high occurrence of osteoporotic fractures ${ }^{(18)}$, severe infections ${ }^{(19)}$, a distinct rise in the occurrence of IHD $^{(20,21)}$ and dental diseases ${ }^{(22)}$. These diseases may be related to long-term low $\mathrm{Ca}$ intake despite being managed short term by an adaption of the homoeostatic mechanisms.

This led us to explore the associations between $\mathrm{Ca}, \mathrm{PTH}$ and 25OHD in serum among Greenlanders and non-Greenlanders living in the capital city Nuuk in West Greenland and in the rural Ammassalik district in East Greenland as major players in Ca homoeostasis include PTH and vitamin D.

\section{Methods}

\section{Area of investigation, subjects and procedures}

We included subjects living in Ammassalik district $\left(65^{\circ} 35^{\prime} \mathrm{N}\right.$ $\left.38^{\circ} 00^{\prime} \mathrm{W}\right)$ in East Greenland or in the capital city Nuuk in West Greenland $\left(64^{\circ} 15^{\prime} \mathrm{N} 51^{\circ} 35^{\prime} \mathrm{W}\right)$.

We invited 50- to 69-year-old men and women, Greenlanders (all Inuit) and not Greenlanders (all Caucasian Danes), recorded, selected and living on the address as described in detail previously $^{(7,11)}$. The places selected for investigation were Nuuk, Tasiilaq and the settlements Tiniteqilaaq, Sermiligaaq, Kulusuk and Kuummiut in Ammassalik district. Only settlements with more than fifteen inhabitants in the selected age group were included. In Nuuk, names and addresses were obtained from the hospital registration system that keeps records of all inhabitants of Nuuk. A random sample of $25 \%$ of the total population aged 50-69 years was selected. The hospital registration system had not been regularly updated and for the investigation in Ammassalik names and addresses were obtained from the National Civil Registration System in which every person living in Denmark, the Faeroe Islands and Greenland is registered. We invited 225 persons in Nuuk, 184 in Tasiilaq, nineteen in Tiniteqilaaq, twenty-eight in Sermiligaaq, fifty-two in Kulusuk and fifty-three in Kuummiut, and 95\% participated. A Greenlander was defined as an individual born in Greenland with both parents born in Greenland and is hereafter named Inuit.

This study was conducted according to the guidelines laid down in the Declaration of Helsinki, and the Commission for Scientific Research in Greenland approved the procedures (reference no. 2010-8). All subjects gave informed written consent in Danish or Greenlandic by participant choice.

The local hospital porter or the nursing station attendant delivered a letter of invitation. The investigation took place at the local hospital or nursing station or by request as home visits. The physical examination performed included height without shoes, weight in indoor clothing and recording of major disabilities. Participants were interviewed by a Greenlandic interpreter or by one of the investigating doctors completing a questionnaire in either Danish or Greenlandic as appropriate for the participant. Information regarding age and sex was obtained from the National Civil Registration System. Information on lifestyle patterns and dietary habits was obtained by questionnaires. Questions were asked as written in the questionnaires. The same interpreter was used at all sites.

\section{Dietary habits}

Dietary habits were assessed using an interview-based FFQ. It included seven traditional Inuit (seal, whale, wild fowl, fish, reindeer, musk ox and hare) and seven imported food items (pre-cooked meals, potatoes, vegetables, butter, cheese, egg and fresh fruit). These were selected based on their contribution to the diet in Greenland ${ }^{(23)}$. Each food item was categorised into one of six frequency categories from never to daily intake. A frequency score was calculated based on the average number of days per month it was ingested ${ }^{(7,23)}$. Inuit food items scored positively and imported food items scored negatively. The sum of frequency scores for all food items consumed by each participant was calculated and individuals were categorised into quintiles - diet group 1: $>80 \%$ Inuit food item scores; 2: 60-80\%; 3: 40-60\%; 4: 20-40\%; 5: <20\% Inuit food item scores. The scale was based on high scores for predominantly traditional Inuit food items and low scores for imported food items. Scores were validated by cross-check questions, as well as by the use of iodine as a biomarker of the intake of the iodine-rich traditional Inuit foods ${ }^{(11,24)}$. The intake of vitamin-D-containing supplements was evaluated from the frequency of intake.

\section{Blood sampling and assays}

Venous blood samples were obtained by venepuncture using minimal tourniquet. Whole blood was allowed to clot, spun using a portable centrifuge and serum was separated and stored at $-20^{\circ} \mathrm{C}$ until analysis. Samples were stored on the roof of the nursing stations in the settlements in East Greenland as the temperature was below $-20^{\circ} \mathrm{C}$. The bag with samples had to be kept on the roof to be out of reach of sledge dogs.

$\mathrm{Ca}$ and albumin were measured using standard laboratory methods (Hitachi 917; Roche Diagnostics Corp.). Intra-/interassay CV were $0 \cdot 9 / 1.5 \%$ for $\mathrm{Ca}$ and $1.5 / 2 \cdot 1 \%$ for albumin (information supplied by manufacturer). Approximately $50 \%$ of total serum $\mathrm{Ca}$ in blood is bound to proteins, and only the nonbound $\mathrm{Ca}$ is biologically active and tightly controlled by hormonal mechanisms. We thus adjusted for individual variations in albumin (adjusted serum $\mathrm{Ca}(\mathrm{mmol} / \mathrm{l})=$ total serum $\mathrm{Ca}$ $(\mathrm{mmol} / \mathrm{l})-0.00086 \times(650-$ serum albumin $(\mu \mathrm{mol} / \mathrm{l})))$. PTH was measured using Immulite automated analyser (Diagnostic Products Corporation) with an overall $\mathrm{CV}$ below 7\%. Serum $25 \mathrm{OHD}$ levels were analysed by isotope dilution liquid chromatography-tandem MS with inter-assay CV of 8.6 and $9.4 \%$ for $25 \mathrm{OHD}_{2}$ and $25 \mathrm{OHD}_{3}{ }^{(25)}$. Calibrators traceable to National Institute of Standards and Technology standard reference material (SRM972) were used for external quality assurance (Chromsystems) $^{(25)}$.

\section{Statistics}

Results are given as medians and 25th and 75th percentiles. Groups were compared using non-parametric statistics: the $\chi^{2}$ test for comparison of proportions, the Mann-Whitney $U$ test for comparison of two groups and the Kruskal-Wallis test for comparing several groups. Distributions were tested using the 
Kolmogorov-Smirnov test and logarithmic transformation was performed on data not following the Gaussian distribution (Ca and PTH) for further analysis. Bartlett's test was used to test for homogeneity of variance to support description of dispersion by standard deviations or interquartile ranges (IQR). Linear regression models were used with PTH and Ca entered as dependent variable. Explanatory variables entered were ethnic origin, diet group, alcohol intake, smoking habits, sex, age, $25 \mathrm{OHD}$ in serum and BMI. PTH was included for investigation of $\mathrm{Ca}$, and $\mathrm{Ca}$ was included for investigation of PTH. Diet and origin were investigated in separate models in the multivariate linear regression analysis because of covariance. Random selection of participants in Nuuk was performed using MedStat (Astra). Data were processed and analysed using Corel Quattro Pro 8 (Corel Corporation) and the Statistical Package for the Social Sciences version 13.0 (SPSS Inc.). A $P$ value $<0.05$ was considered significant.

\section{Results}

In all, $1 \%$ of the population of Greenland was invited and $95 \%$ participated. Table 1 lists the characteristics of the participants. Seven non-Inuit had one parent born in Greenland, whereas ninety-four had neither parent born in Greenland. Non-Inuit were mainly skilled labour from Denmark and thus included more men than women $(P<0 \cdot 001)$. This also influenced the age distribution because some leave Greenland at retirement. Alcohol intake was higher among Caucasian Danes and more Inuit were smokers. Hunting and dietary habits differed with geography. Dietary habits differed markedly both between Inuit and Caucasian Danes $(P<0.001)$ and among Inuit groups $(P<0 \cdot 001)$. Thus, $22 \%$ of Caucasian Danes reported a food frequency score of $40 \%$ Inuit foods or more, whereas this was $86 \%$ of Inuit in Nuuk and $99 \%$ of Inuit in Tasiilaq and settlements. 25OHD groups are detailed in Table 1, and Table 2 gives

Table 1. Descriptives of participants in the survey of diet and calcium homoeostasis in 50- to 69-year-old residents in East and West Greenland (Numbers and percentages; mean values and standard deviations)

\begin{tabular}{|c|c|c|c|c|c|c|c|c|c|c|c|}
\hline & \multicolumn{2}{|c|}{ Non-Inuit† } & \multicolumn{2}{|c|}{ Inuit in Nuuk } & \multicolumn{2}{|c|}{ Inuit in Tasiilaq } & \multicolumn{2}{|c|}{ Inuit in settlements } & \multicolumn{3}{|c|}{$P^{*}$} \\
\hline & $n$ & $\%$ & $n$ & $\%$ & $n$ & $\%$ & $n$ & $\%$ & Inuit v. Caucasians & Among all groups & Among Inuit groups \\
\hline Participants & 101 & 100 & 150 & 100 & 141 & 100 & 143 & 100 & & & \\
\hline \multicolumn{12}{|l|}{ Sex } \\
\hline Men & 80 & $79 \cdot 2$ & 70 & $46 \cdot 7$ & 80 & $56 \cdot 7$ & 79 & $55 \cdot 2$ & & & \\
\hline Women & 21 & $20 \cdot 8$ & 80 & $53 \cdot 3$ & 61 & $43 \cdot 3$ & 64 & $44 \cdot 8$ & $<0.001$ & $<0.001$ & 0.17 \\
\hline \multicolumn{12}{|l|}{ Age (years) } \\
\hline $50-59$ & 85 & $84 \cdot 2$ & 87 & $58 \cdot 0$ & 87 & $61 \cdot 7$ & 85 & $59 \cdot 4$ & & & \\
\hline $60-69$ & 16 & $15 \cdot 8$ & 63 & $42 \cdot 0$ & 54 & $38 \cdot 3$ & 58 & $40 \cdot 6$ & $<0.001$ & $<0.001$ & 0.81 \\
\hline \multicolumn{12}{|l|}{ Smokerł } \\
\hline Never & 26 & $25 \cdot 7$ & 22 & $14 \cdot 8$ & 19 & 13.5 & 15 & 10.5 & & & \\
\hline Past & 18 & $17 \cdot 8$ & 16 & $10 \cdot 7$ & 14 & 9.9 & 19 & $13 \cdot 3$ & & & \\
\hline Present & 57 & $55 \cdot 3$ & 111 & 74.5 & 108 & $76 \cdot 6$ & 109 & $76 \cdot 2$ & $<0.001$ & 0.008 & 0.75 \\
\hline$<10$ & 10 & 9.9 & 70 & $47 \cdot 0$ & 59 & $41 \cdot 8$ & 59 & $41 \cdot 3$ & & & \\
\hline $10-20$ & 31 & 30.7 & 35 & 23.5 & 44 & $31 \cdot 2$ & 45 & 31.5 & & & \\
\hline$>20$ & 16 & $15 \cdot 8$ & 6 & $4 \cdot 0$ & 5 & 3.5 & 5 & 3.5 & & & \\
\hline \multicolumn{12}{|l|}{ Alcohol use§ } \\
\hline Never & 11 & $11 \cdot 0$ & 20 & $13 \cdot 9$ & 36 & 25.9 & 73 & 51.0 & & & \\
\hline $0-7$ units & 45 & $45 \cdot 0$ & 72 & $50 \cdot 0$ & 52 & 37.4 & 21 & 14.7 & & & \\
\hline $8-14$ units & 25 & $25 \cdot 0$ & 40 & $27 \cdot 8$ & 35 & $25 \cdot 2$ & 20 & $14 \cdot 0$ & & & \\
\hline $15-21$ units & 7 & $7 \cdot 0$ & 10 & 6.9 & 11 & 7.9 & 17 & 11.9 & & & \\
\hline$>21$ units & 12 & $12 \cdot 0$ & 2 & 1.4 & 5 & 3.6 & 12 & $8 \cdot 4$ & $<0.001$ & $<0.001$ & $<0.001$ \\
\hline \multicolumn{12}{|c|}{ Greenlandic diet score (\%)\| } \\
\hline$>80$ & 2 & $2 \cdot 0$ & 43 & $28 \cdot 7$ & 93 & $66 \cdot 0$ & 103 & $72 \cdot 0$ & & & \\
\hline $60-80$ & 6 & $5 \cdot 9$ & 45 & $30 \cdot 0$ & 29 & $20 \cdot 6$ & 30 & $21 \cdot 0$ & & & \\
\hline $40-60$ & 14 & $13 \cdot 9$ & 41 & $27 \cdot 3$ & 17 & $12 \cdot 1$ & 8 & $5 \cdot 6$ & & & \\
\hline $20-40$ & 41 & $40 \cdot 6$ & 17 & $11 \cdot 3$ & 1 & 0.7 & 2 & 1.4 & & & \\
\hline$<20$ & 38 & $37 \cdot 6$ & 4 & $2 \cdot 7$ & 1 & 0.7 & 0 & 0.0 & $<0.001$ & $<0.001$ & $<0.001$ \\
\hline \multicolumn{12}{|l|}{ Diet scores } \\
\hline Mean & \multicolumn{2}{|c|}{-325} & \multicolumn{2}{|c|}{-178} & \multicolumn{2}{|c|}{-114} & \multicolumn{2}{|c|}{-19} & & & \\
\hline SD & \multicolumn{2}{|c|}{101} & \multicolumn{2}{|c|}{168} & \multicolumn{2}{|c|}{125} & \multicolumn{2}{|c|}{94} & & & \\
\hline \multicolumn{12}{|l|}{ Huntingף } \\
\hline Trade & 2 & 2.0 & 8 & $5 \cdot 5$ & 22 & $15 \cdot 8$ & 45 & 31.5 & & & \\
\hline Leisure & 39 & $38 \cdot 6$ & 44 & $30 \cdot 3$ & 52 & 37.4 & 53 & $37 \cdot 1$ & & & \\
\hline Rarely & 60 & $59 \cdot 4$ & 93 & $64 \cdot 1$ & 65 & $46 \cdot 8$ & 45 & 31.5 & $<0.001$ & $<0.001$ & $<0.001$ \\
\hline \multicolumn{12}{|c|}{ Vitamin D (nм)†† } \\
\hline$<20$ & 12 & 11.9 & 0 & 0.0 & 2 & 1.4 & 0 & 0.0 & & & \\
\hline$<50$ & 69 & $69 \cdot 0$ & 23 & $15 \cdot 4$ & 37 & $26 \cdot 8$ & 37 & $26 \cdot 2$ & & & \\
\hline$>50$ & 31 & $31 \cdot 0$ & 126 & $84 \cdot 6$ & 101 & $73 \cdot 2$ & 104 & $73 \cdot 8$ & $<0.001$ & $<0.001$ & 0.033 \\
\hline
\end{tabular}

${ }^{*} x^{2}$ Test.

$\dagger$ Including seven participants of mixed origin.

$\ddagger$ Information missing in one participant in Nuuk.

$\S$ Estimated units of alcohol per week. Information missing in nine (1/6/2/0) participants. Comparison above $v$. below 7 units/week.

II Diet groups $<20,20-40$ and $40-60 \%$ combined for $x^{2}$ test.

I Information missing in seven (0/5/2/0) participants. Trade and leisure groups merged for statistical analysis.

†† Information missing in seven (1/1/3/2) participants. Statistical comparison performed for below $v$. above $50 \mathrm{nM}$. 
the medians and 25, 75 percentiles, in addition to means and standard deviations, of $25 \mathrm{OHD}, \mathrm{PTH}$ and $\mathrm{Ca}$, total and corrected for individual albumin levels, in the participant groups

Total serum Ca was lower in Inuit than in Caucasian Danes and did not differ between Inuit groups (Table 2). Albumin adjustment augmented the ethnic difference. In addition to the difference in mean, dispersion of $\mathrm{Ca}$ differed with ethnicity, with higher SD and IQR in Inuit compared with Caucasian Danes $(P<0.01)$ and no difference between Inuit groups (NS). PTH differed between Inuit and Caucasian Danes, with a higher level in the latter (Table 2). In addition, PTH did not differ between Inuit groups. Dispersion of PTH differed between Inuit and Caucasian Danes $(P<0 \cdot 01)$ and among Inuit groups $(P<0 \cdot 01)$. Serum 25OHD levels differed with ethnicity (Table 2 ) and between Inuit groups, as did dispersion both with ethnicity $(P=0.01)$ and between Inuit groups $(P<0.01)$.

Fig. 1 illustrates the distinct ethnic difference in the association between serum 25OHD and PTH in the serum 25OHD insufficiency range. Although PTH rose with low serum 25OHD in Caucasian Danes, this did not occur in Inuit, and PTH differed in the 69/97 Caucasian Danes/Inuit with serum 25OHD $<50 \mathrm{nmol} / 1(P=0 \cdot 001)$.

Table 3 lists factors important to $\mathrm{Ca}$ and PTH in serum as evaluated in crude and adjusted analysis. The factors of main importance to $\mathrm{Ca}$ levels were ethnic origin, diet and serum 25OHD after adjusting for also sex, age and PTH. Serum PTH levels were influenced by ethnic origin, diet and serum 25OHD in the adjusted analysis that included also BMI and smoking. As for $P-25 \mathrm{OHD}$, a main association was seen with diet $(P<0.001)$, whereas some association was seen with $\mathrm{Ca}$ $(P=0.021)$ and PTH $(P=0.007)$

\section{Discussion}

Previous findings suggested an ethnic influence on Ca homoeostasis in Inuit compared with Caucasian Danes by a difference in serum $\mathrm{Ca}^{(6,16)}$, an influence of ethnicity on $\mathrm{PTH}^{(6)}$ and by the fact that ethnic origin modified the influence of diet on serum $25 \mathrm{OHD}$ levels ${ }^{(7)}$. These hints all point to an importance of ethnic origin for Ca homoeostasis. In addition, they are in resonance with the intuitive understanding of an adaption among Arctic residents to an environment low in dietary $\mathrm{Ca}$ and possibly vitamin D. Exploring this topic may provide further insight into our understanding of Ca homoeostasis.

The conductor of the Ca homoeostasis orchestra is PTH. Ethnicity, diet and serum 25OHD associated with PTH in our data. The differences in slope were limited, but it is intriguing that the larger beta was seen with ethnicity. The number of subjects with $25 \mathrm{OHD}$ in the range of insufficiency differed between Inuit and Caucasians (22.7\%, ninety-seven Inuit; $69 \%$, sixty-nine Caucasians), but it was clearly sufficient to detect a statistically significant difference in PTH, as well as in Ca. It seems thus that ethnicity could have a major influence on $\mathrm{Ca}$ homoeostasis when comparing Caucasians and Inuit. Interestingly, the same accounted for $\mathrm{Ca}$ that had the slightly larger beta coefficient for PTH. An influence of ethnic origin on $\mathrm{Ca}$ homoeostasis is thus a likely trait in our data. This is in keeping with the findings by Rejnmark et al. of lower

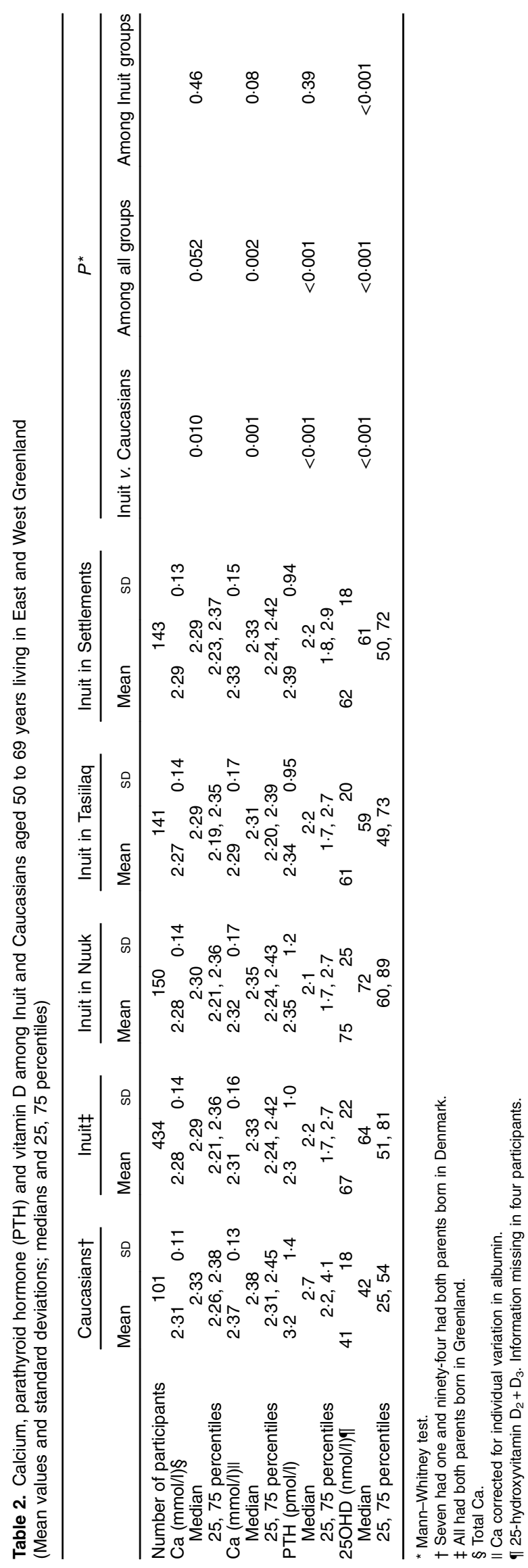


PTH among Inuit in a study comparing forty-three Caucasian Danes in Denmark with Inuit in Denmark and Greenland with a focus on seasonal differences ${ }^{(6)}$. Despite the lower PTH, they found both higher 1,25-dihydroxyvitamin D
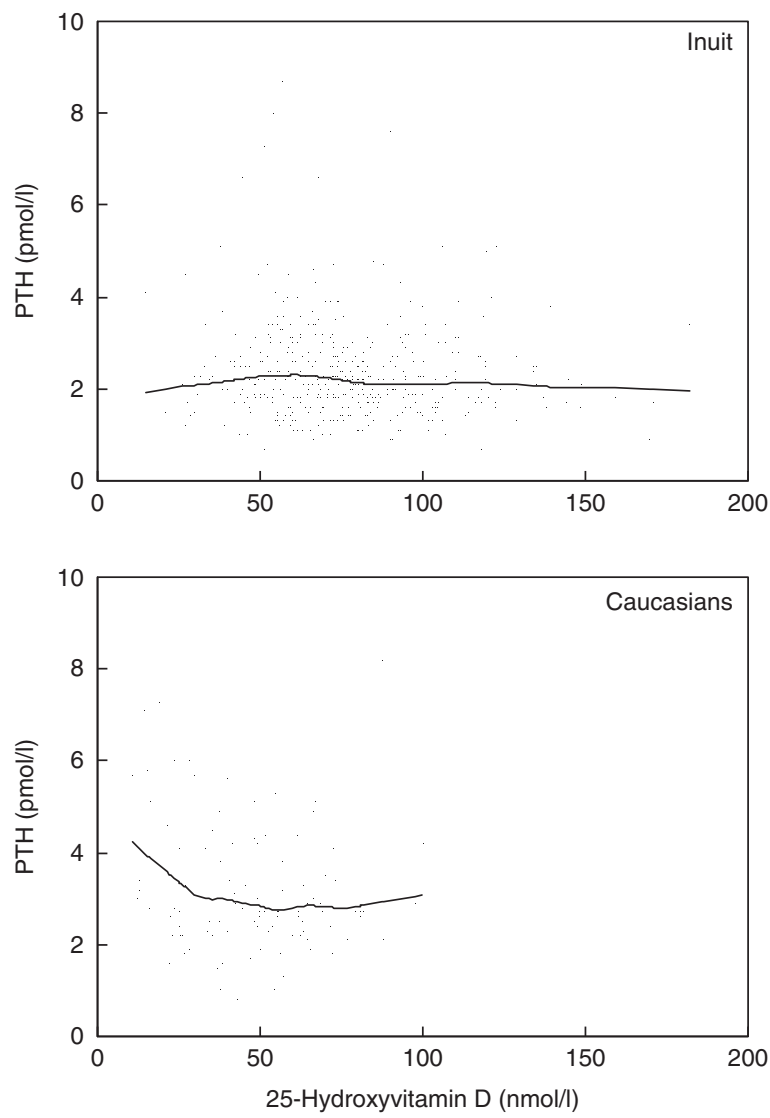

Fig. 1. Association between parathyroid hormone $(\mathrm{PTH})$ and vitamin $\mathrm{D}$ differed between individuals of Greenlandic descent (Inuit, upper panel) and migrants (Caucasians, lower panel) living in Greenland. and lower $\mathrm{Ca}$ in serum among Inuit compared with Caucasian Danes. This conforms to the hypothesis that Inuit has adapted to a low-Ca environment with augmented absorption of dietary $\mathrm{Ca}$ from the intestines and promoted Ca fluxes into blood from kidney and bones mediated by the slightly higher 1,25-dihydroxyvitamin $\mathrm{D}$. These findings encourage further study.

A number of mechanisms may contribute to the differences with ethnic origin. An altered vitamin-D-binding protein has been demonstrated among Asians compared with other ethnic groups $^{(26)}$. Inuit are of Asian descent and they could be speculated to have different levels of vitamin-D-binding protein. The latter may influence 25OHD metabolism ${ }^{(27)}$, and 25OHD half-life associated with vitamin-D-binding protein with ethnic differences between Gambian subjects and Caucasians ${ }^{(28)}$. However, differences in vitamin-D-binding protein levels were more marked within Inuit groups than with ethnic origin in the previous study ${ }^{(6)}$. The group size was limited in that study but a marked difference would have been detected. Hence, this mechanism is less likely, as vitamin-D-binding protein levels were similar in Inuit and Caucasian Danes.

An altered 1- $\alpha$-hydroxylase activity in Inuit compared with Caucasian Danes is another mechanism to consider. Higher levels of 1,25-dihydroxyvitamin $\mathrm{D}$ in Inuit compared with Caucasian Danes was demonstrated despite lower levels of serum $25 \mathrm{OHD}^{(6)}$. The higher 1,25-dihydroxyvitamin D augments the intestinal absorption of $\mathrm{Ca}$ and suppresses PTH secretion. This is in keeping with our finding of a lower PTH among Inuit than Caucasian Danes ${ }^{(6)}$. Nevertheless, this association needs further evaluation as other mechanisms may influence PTH. These include differences in PTH activity, PTH-related proteins influencing the PTH receptor and a genetic variant in Inuit. The latter would be in line with the genetic signature of adaptation to a high-fat diet demonstrated recently ${ }^{(29)}$. Similar mechanisms could be speculated to be at play with adaptation to a low-Ca diet. However, a number of

Table 3. Factors associated with calcium and parathyroid hormone (PTH) in 50- to 69-year-old residents in Greenland

\begin{tabular}{|c|c|c|c|c|c|c|c|c|}
\hline & \multicolumn{4}{|c|}{$\mathrm{Ca}^{*}$} & \multicolumn{4}{|c|}{ PTH } \\
\hline & \multicolumn{2}{|c|}{ Univariate model } & \multicolumn{2}{|c|}{ Multivariate model $\dagger$} & \multicolumn{2}{|c|}{ Univariate model } & \multicolumn{2}{|c|}{ Multivariate model $†$} \\
\hline & $\beta \ddagger$ & $P$ & $\beta \ddagger$ & $P$ & $\beta \ddagger$ & $P$ & $\beta \ddagger$ & $P$ \\
\hline $\mathrm{Ca}^{*}$ & & & & & 0.02 & NS & -0.05 & NS \\
\hline PTH & 0.02 & NS & -0.04 & NS & & & & \\
\hline $25 \mathrm{OHD}_{2}$ and $\mathrm{D}_{3}$ & 0.10 & 0.018 & 0.15 & 0.001 & -0.21 & $<0.001$ & -0.17 & $<0.001$ \\
\hline Ethnicity & 0.13 & 0.004 & 0.22 & $<0.001$ & 0.28 & $<0.001$ & 0.27 & $<0.001$ \\
\hline Age (years) & -0.08 & 0.061 & 0.00 & NS & -0.01 & NS & 0.06 & NS \\
\hline Sex & 0.01 & NS & 0.10 & 0.036 & -0.07 & 0.10 & -0.01 & NS \\
\hline BMI $\left(\mathrm{kg} / \mathrm{m}^{2}\right)$ & 0.10 & 0.021 & 0.05 & NS & 0.02 & NS & 0.01 & NS \\
\hline Diet§ & 0.14 & 0.002 & 0.19 & $<0.001$ & 0.19 & $<0.001$ & 0.20 & $<0.001$ \\
\hline Alcohol & -0.02 & NS & -0.04 & NS & 0.01 & NS & -0.01 & NS \\
\hline Smoker & 0.01 & NS & 0.04 & NS & -0.03 & NS & -0.02 & NS \\
\hline
\end{tabular}

25OHD, 25-hydroxyvitamin D.

NS $P>0.1$.

* Ca corrected for individual variation in albumin.

† Dependent variables were serum $\mathrm{Ca} / \mathrm{PTH}$ and explanatory variables were age, sex, serum PTH/Ca, alcohol intake, diet and ethnicity. Diet and origin were tested in separate models owing to collinearity.

$\ddagger \beta$ (Regression) coefficients were Inuit/non-Inuit; advancing age; men/women; rising BMI; decreasing Inuit diet; increasing alcohol intake; and smoking with groups as given in Table 1 . $\S$ Diet based on diet groups calculated from the frequency of intake of seven Inuit and seven imported food items - diet group 1: 80\%; 2 : $60-80 \% ; 3: 40-60 \% ; 4: 20-40 \%$; 5: 0-20\% Inuit food frequency scores. 
physiologic factors may also influence PTH, including smoking and obesity.

Body build differs between Inuit and Caucasians as Inuit have shorter limbs relative to the torso ${ }^{(30,31)}$ and they may present with higher BMI for the same degree of metabolic disturbances $^{(32)}$. These ethnic peculiarities did not influence PTH as evaluated in the adjusted comparisons in our data.

Smoking rates are high in Greenland ${ }^{(33,34)}$, and about $75 \%$ of Inuit participants in our study were present smokers. The relatively high rate of $56 \%$ smokers among Caucasians was still lower than among Inuit. Yet, smoking did not influence PTH in our data.

The lower $\mathrm{Ca}$ and PTH in serum in Inuit compared with Caucasians has the potential to influence bones and the risk for osteoporosis. Available data suggest no difference in BMD between Inuit and Caucasian Danes ${ }^{(35)}$, similar fracture rates ${ }^{(18)}$ and similar impact of risk factors for osteoporosis ${ }^{(34)}$. Thus, the limited data available do not suggest a difference in the occurrence of bone diseases between Inuit and Caucasian Danes. However, vitamin D plays a pivotal role in skeletal health $^{(1,2)}$, and sufficient $25 \mathrm{OHD}$ levels in Inuit ${ }^{(7,36)}$ may contribute to this finding. $25 \mathrm{OHD}$ is ample in the traditional Inuit foods that comprise mainly marine mammals and fish in addition to caribou and birds ${ }^{(36,23)}$, but ethnicity had an impact on the influence of diet on serum 25OHD levels ${ }^{(7)}$. We included only subjects aged 50 through 69 years. This might underestimate the impact of the transition away from traditional foods as older Inuit have a higher intake of traditional Inuit foods $^{(11,37)}$. Consequently, it may be speculated that the dietary transition in Arctic societies poses a particular risk for skeletal diseases among Inuit. This encourages attention to the influence of dietary transition on bone metabolism and diseases.

The older age group included contributed to a high participation rate of $95 \%$ in this population-based exploratory survey, which supports the validity of the findings. This is further supported by the inclusion of populations at the extremes of transition of societies in Greenland from the capital city Nuuk in West Greenland to remote settlements in East Greenland. We did not measure 1,25-hydroxylase activity, vitamin-D-binding protein, PTH-related protein or further measures of Ca homoeostasis. We recommend this for future studies of influence of ethnic origin on Ca homoeostasis.

An influence of ethnic origin has been debated in relation to body build ${ }^{(30)}$, bone mineral density ${ }^{(35)}$, bone metabolism ${ }^{(36,38)}$, renal function ${ }^{(33)}$ and lipid metabolism ${ }^{(29)}$. Although differences have been demonstrated ${ }^{(29,30,35,38,39)}$, the cause for such differences has been rather a question of filtering out environmental factors to settle whether genetic factors are at play. We conducted multivariate analysis to adjust for relevant environmental factors. However, the importance of genetics remains to be determined.

In conclusion, we found different $\mathrm{Ca}$ and PTH levels in serum in Inuit and Caucasian Danes. A rise in PTH was seen with low serum 25OHD levels in Caucasian Danes but not in Inuit, and ethnic origin was a major determinant of PTH and Ca in our data in addition to diet and $P-25 \mathrm{OHD}$. The difference in serum $\mathrm{Ca}$ is indicative of an influence of ethnicity on $\mathrm{Ca}$ homoeostasis in view of the powerful, interactive homoeostatic mechanisms to maintain serum Ca within narrow limits. This is further supported by the ethnic differences in PTH level and in PTH response to low 25OHD. Recommendations are to follow up on Arctic populations to assess the impact of transition in dietary habits on Ca homoeostasis and skeletal health, and to evaluate mechanisms underlying the ethnic influence on Ca homoeostasis.

\section{Acknowledgements}

The authors gratefully acknowledge Karoline Berglund for her enthusiasm and thorough interviewing of Inuit. The authors are grateful for invaluable support from lægeklinikken in Nuuk, from Hans Chr. Florian Sørensen and the staff at the hospital in Tasiilaq, and from the staff at the nursing stations in Tiniteqilaaq, Sermiligaaq, Kuummiut and Kulusuk. Peter Laurberg contributed to project conception, study design, raising of funds and data collection. Sadly, he tragically passed away in 2016 and did not contribute to finalising this work that was very dear to him.

This study was supported by grants from Greenland Government; Karen Elise Jensen Foundation; Northern Jutland Research Foundation; and Aalborg City Christmas Lottery.

S. A.: project conception, study design, raising of funds, data collection, analysis of data and writing of the manuscript. P. N., K. F. R. and M. B. L.: data analysis; P. N., K. F. R., I. F., N. A., M. E. J., L. K. S. and M. B. L.: reviewing of the manuscript; I. F. and L. K. S.: interpretation of data; N. A. and M. E. J: intellectual contribution; and M. B. L.: project conception.

The authors declare that there are no conflicts of interest.

\section{References}

1. Holick MF (2007) Vitamin D deficiency. $N$ Engl J Med 357, 266-281.

2. Adams JS \& Hewison M (2010) Update in vitamin D. J Clin Endocrinol Metab 95, 471-478.

3. Hagenau T, Vest R, Gissel TN, et al. (2009) Global vitamin D levels in relation to age, gender, skin pigmentation and latitude: an ecologic meta-regression analysis. Osteoporos Int 20, $133-140$

4. El Hayek Fares J \& Weiler HA (2016) Implications of the nutrition transition for vitamin $D$ intake and status in Aboriginal groups in the Canadian Arctic. Nutr Rev 74, $571-583$

5. Andersen S, Jakobsen A, Rex HL, et al. (2013) Vitamin D in Greenland - dermal and dietary donations. Int J Circumpolar Health 72, 21225.

6. Rejnmark L, Jørgensen ME, Pedersen MB, et al. (2004) Vitamin D insufficiency in Greenlanders on a westernized fare: ethnic differences in calcitropic hormones between Greenlanders and Danes. Calcif Tissue Int 74, 255-263.

7. Andersen S, Laurberg P, Hvingel B, et al. (2013) Vitamin D status in Greenland is influenced by diet and ethnicity: a population-based survey in an Arctic society in transition. Br J Nutr 109, 928-935.

8. Keiver KM, Draper HH \& Ronald KJ (1988) Vitamin D metabolism in the hooded seal (Cystophora cristata). Nutr $\mathbf{1 1 8}$, 332-341.

9. Lu Z, Chen TC, Zhang A, et al. (2007) An evaluation of the vitamin $\mathrm{D}_{3}$ content in fish: is the vitamin $\mathrm{D}$ content adequate to satisfy the dietary requirement for vitamin D? I Steroid Biochem Mol Biol 103, 642-644. 
10. Kuhnlein HV, Receveur O, Soueida R, et al. (2008) Unique patterns of dietary adequacy in three cultures of Canadian Arctic indigenous peoples. Public Health Nutr 11, 349-360.

11. Andersen S, Hvingel B, Kleinschmidt K, et al. (2005) Changes in iodine excretion in 50-69-y-old denizens of an Arctic society in transition and iodine excretion as a biomarker of the frequency of consumption of traditional Inuit foods. Am J Clin Nutr 81, 656-663.

12. Andersen S, Jakobsen A \& Laurberg P (2013) Vitamin D status in North Greenland is influenced by diet and season: indicators of dermal 25-hydroxy vitamin D production north of the Arctic Circle. Br J Nutr 111, 50-57.

13. Sharma S, Hopping BN, Roache C, et al. (2013) Nutrient intakes, major food sources and dietary inadequacies of Inuit adults living in three remote communities in Nunavut, Canada. J Hum Nutr Diet 26, 578-586.

14. Johnson JS, Nobmann ED, Asay E, et al. (2009) Dietary intake of Alaska Native people in two regions and implications for health: the Alaska Native Dietary and Subsistence Food Assessment Project. Int J Circumplar Health 68 , 109-122.

15. Deutch B, Dyerberg J, Pedersen HS, et al. (2007) Traditional and modern Greenlandic food - dietary composition, nutrients and contaminants. Sci Total Environ 384, 106-109.

16. Jeppesen BB \& Harvald B (1983) Serum calcium in Greenland Eskimos. Acta Med Scand 214, 99-101.

17. Bringhurst FR, Demay MB \& Kronenberg HM (2016) Calcium and phosphate homeostasis. In Williams Textbook of Endocrinology, 13th ed. pp. 1254-1322 [S Melmed, KS Polonsky, PR Larsen and HM Kronenberg, editors]. Amsterdam: Elsevier.

18. Sorensen VN, Wojtek P, Pedersen D, et al. (2015) An efficient case finding strategy to diagnose osteoporosis in a developing society with low treatment frequency. J Endocrinol Invest 38, 841-847.

19. Meyer A, Ladefoged K, Poulsen P, et al. (2008) Populationbased survey of invasive bacterial diseases, Greenland, 1995-2004. Emerg Infect Dis 14, 76-79.

20. Kjaergaard M, Andersen S, Holten M, et al. (2009) Low occurrence of ischemic heart disease among Inuit around 1963 suggested from ECG among 1851 East Greenland Inuit. Atherosclerosis 203, 599-603.

21. Jorgensen ME, Bjerregaard P, Kjaergaard JJ, et al. (2008) High prevalence of markers of coronary heart disease among Greenland Inuit. Atherosclerosis 196, 772-778.

22. Petersen P \& Christensen LB (2006) Cariesforekomsten i tidsperspektiv hos børn og unge i Grønland - udfordringer for forebyggelse og sundhedsfremme (Caries ocurrence among children and adolscent in Greenland - challenges in prevention and health promotion). Tandlaegebladet (Danish Dental Journal) 110, 486-493.

23. Pars T (2000) Forbruget af traditionelle grønlandske fødevarer i Vestgrønland. (Contemporary use of traditional foods among Greenlandic Inuit). Doctoral dissertation, University of Copenhagen (in Danish).

24. Andersen S, Hvingel B \& Laurberg P (2002) Iodine content of traditional Greenlandic food items and tap water in East and West Greenland. Int J Circumpolar Health 6, 332-340.

25. Hojskov CS, Heickendorff L \& Moller HJ (2010) High-throughput liquid-liquid extraction and LCMSMS assay for determination of circulating $25(\mathrm{OH})$ vitamin $\mathrm{D}_{3}$ and D2 in the routine clinical laboratory. Clin Chim Acta 411, $114-116$.

26. Chen LZ, Easteal S, Board PG, et al. (1990) Albuminvitamin D-binding protein haplotypes in Asian-Pacific populations. Hum Genet 85, 89-97.

27. Jones KS, Schoenmakers I, Assar S, et al. (2014) 25(OH)D2 half-life is shorter than 25(OH)D3 half-life and is influenced by vitamin D binding protein concentration and genotype. J Clin Endocrinol Metab 99, 3373-3381.

28. Jones KS, Assar S, Vanderschueren D, et al. (2015) Predictors of 25(OH)D half-life and plasma 25(OH)D concentration in The Gambia and the UK. Osteoporos Int 26, $1137-1146$.

29. Fumagalli M, Moltke I, Grarup N, et al. (2015) Greenlandic Inuit show genetic signatures of diet and climate adaptation. Science 349, 1343-1347.

30. Andersen S, Rex KF, Noahsen P, et al. (2013) Raised BMI cut-off for overweight in Greenland Inuit - a review. Int $J$ Circumpolar Health 72, 21086.

31. Andersen S, Mulvad G, Pedersen HS, et al. (2004) Gender diversity in developing overweight over 35 years of westernization in an Inuit hunter cohort and ethno-specific body mass index for evaluation of body-weight abnormalities. EurJ Endocrinol 151, 735-740.

32. Noahsen P \& Andersen S (2013) Ethnicity influences BMI as evaluated from reported serum lipid values in Inuit and nonInuit: raised upper limit of BMI in Inuit? Ethnicity \& Disease 23, 77-82.

33. Bjerregaard P, Jørgensen M \& Borch-Johnsen K (2007) Cardiovascular risk amongst migrant and non-migrant Greenland Inuit in a gender perspective. Scand J Public Health 35, 380-386.

34. Jakobsen A, Laurberg P, Vestergaard P, et al. (2013) Clinical risk factors for osteoporosis are common among elderly people in Nuuk, Greenland. Int J Circumpolar Health 72, 19596.

35. Andersen S, Boeskov E \& Laurberg P (2005) Ethnic differences in bone mineral density between Inuit and Caucasians in North Greenland are caused by differences in body size. J Clin Densitom 8, 409-414.

36. Nielsen NO, Bjerregaard P, Rønn PF, et al. (2016) Associations between vitamin $\mathrm{D}$ status and type 2 diabetes measures among Inuit in Greenland may be affected by other factors. PLOS ONE 11, e0152763.

37. Kuhnlein HV, Receveur O, Soueida R, et al. (2004) Arctic indigenous peoples experience the nutrition transition with changing dietary patterns and obesity. J Nutr 124, $1447-1453$.

38. Redmond J, Jarjou LMA, Zhou B, et al. (2014) Ethnic differences in calcium, phosphate and bone metabolism. Proc Nutr Soc 73, 340-351.

39. Andersen S, Dehnfeld M \& Laurberg P (2015) Ethnicity is important for creatinine excretion among Inuit and Caucasians in Greenland. Scand J Clin Lab Invest 75, 44-50. 